\title{
Guerra biológica: uma revisão
}

\section{Valdi Lopes Tutunji ${ }^{1}$}

Quando o principal obstáculo que encaramos é a firme vontade do inimigo, nos parece lógico que cuidemos de destruí-la pelo caminho mais rápido e direto, atacando o moral e a vontade das multidões e também os esforços da produção, não só de material bélico como também aqueles referentes aos meios de vida da retaguarda.

Sherman Miles

RESUMO - Este trabalho discute as causas e conseqüências do uso de agentes biológicos como arma. Levantando sua evolução histórica, descreve suas principais características e analisa as conseqüências da utilização destas armas em cenários civis e militares. Faz uma análise do atual quadro estratégico mundial, apontando caminhos para estabelecer mecanismos internacionais de controle de proliferação mais eficazes, sugerindo iniciativas para prevenir e conter um ataque com estas armas ao território nacional.

Palavras-chave: guerra biológica, arma biológica.

\section{Biological war: a revision}

\begin{abstract}
This work argues the causes and consequences of the use of biological agents as weapon. Surveying its historical evolution, it describes its main features and it analyzes the consequences of the use of these weapons in civil and military scenes. It makes an analysis of the current world-wide strategical conjuncture, pointing paths to establish international mechanisms of more efficient control of proliferation, suggesting initiatives to prevent and to contain an attack with these weapons to the brazilian national territory.
\end{abstract}

Key words: biological war, biological weapon.

A guerra biológica se baseia no uso de microorganismos e de seus produtos tóxicos para provocar lesões, enfermidades e morte em homens, animais e

\footnotetext{
${ }^{1}$ Biólogo. Especialista em Laboratório de Saúde Pública pela Escola Nacional de Saúde Pública/FIOCRUZ. Assistente Superior de Saúde no Hospital de Base do Distrito Federal - Unidade de Patologia ClínicaLaboratório de Microbiologia.

Professor da disciplina de Métodos de Pesquisa em Ciências da Saúde-UniCEUB
} 
plantas. As armas biológicas são únicas em sua habilidade de infligir grande número de baixas, em uma ampla área, com um mínimo de logística, sendo virtualmente indetectáveis.

Nos últimos tempos vieram à tona, pela mídia, inúmeras notícias sobre o uso destas armas, tornando claro o risco de seu uso contra soldados e populações civis. A guerra biológica moderna criou, assim, um novo problema. Ao atingir tropas e populações civis indiscriminadamente, apresenta grande potencial para desencadear epidemias em larga escala, o que as torna armas de destruição em massa, com grande efeito residual.

A análise das características dos últimos conflitos mundiais, das guerras subseqüentes onde foram empregadas armas biológicas e seu uso recente por grupos terroristas, deixa claro que estas armas deverão ter papel preponderante em: guerras declaradas entre países; guerras civis; uso de um governo contra grupos étnicos, religiosos ou contra um indivíduo; uso de um país contra outro país sem estado de guerra declarado; uso por terroristas.

Entre as principais caraterísticas que propiciam a difusão da tecnologia de armas biológicas e o seu conseqüente amplo uso destacam-se: agentes biológicos são relativamente fáceis de produzir, de esconder e podem ser dispersos com uma simples embalagem spray de perfume; pessoas com treinamento básico em microbiologia podem, com poucos recursos, desenvolver armas biológicas simples e eficazes; seu uso é difícil de detectar e comprovar.

No contexto de um conflito declarado ou não, as armas biológicas produzem uma ação total. Intervindo na população civil, podem ocasionar um brusco colapso nas principais fontes de riqueza e produção, reduzindo, limitando ou cessando o abastecimento dos recursos fundamentais ao desenrolar de operações militares.

Neste âmbito, é necessário estabelecer programas de contenção e de treinamento aos profissionais de saúde, civis e militares, afim de prevenir, conter e tratar os eventos causados por armas biológicas. Somente com medidas apropriadas podem-se minimizar os efeitos destas armas, mantendo a estabilidade no seio das populações civis e garantindo o poder de força das unidades de combate.

\section{Pequeno histórico}

Historicamente o uso de armas biológicas tem tido um significativo impacto sobre as operações militares. O mais antigo relato histórico do uso de armas biológicas remonta ao século VI A.C., quando os assírios contaminavam os 
poços de seus inimigos. Esse uso, no entanto, pode ser bem mais antigo, remontando à pré-história, em possíveis tentativas de contaminar águas de rios e fontes com animais mortos.

O episódio descrito no Exxodo como a Quinta Praga, que assolou o Egito faraônico, parece também encaixar-se nas definições de um evento causado por armas biológicas.

Um dos mais conhecidos e desastrosos usos de armas biológicas foi o lançamento de cadáveres vítimas da peste sobre a cidade de Kaffa pelos tártaros, em 1346. A epidemia que se alastrou na cidade, levando os exércitos defensores à rendição e a evacuação em direção a Europa, pode ter dado origem a Peste Negra, que posteriormente se espalhou por todo o continente.

No Século XV, Pizarro presenteou os nativos com roupas contaminadas com varíola; em 1710, tropas russas utilizaram-se da peste contra a Suécia; tropas inglesas também distribuíram cobertores contaminados com varíola, durante a Guerra Franco-Indiana (1754-1767) e durante a Guerra de Independência dos Estados Unidos.

Durante a I Guerra Mundial começa a sistemática utilização da guerra biológica. Neste período, sua eficiência era precária e discutível, dada a grande variedade de resultados. Fatores como dispersão do agente biológico, período de incubação, entre outros, tornavam difícil seu uso generalizado. Nesse período, os alemães empreenderam algumas tentativas para contaminar cavalos das tropas americanas.

Nos anos 40, durante a II ${ }^{\mathrm{a}}$ Grande Guerra, os estudos concernentes ao desenvolvimento, dispersão e efeitos de diferentes agentes biológicos deram um grande salto. Antes mesmo de a guerra começar, os alemães realizaram inúmeros testes de dispersão atmosférica com bactérias não patogênicas. Os japoneses, em 1937, iniciaram um grande programa de guerra biológica, em instalações denominadas "Unidades Sanitárias" espalhadas por todo o sudeste asiático, que perdurou realizando pesquisas até 1945. A mais famosa era conhecida por "Unidade 731". A epidemia de peste que assolou a China durante o ano de 1940 seguiu-se à dispersão de Yersinia pestis por aviões japoneses. Por volta de 1945, o Exército Japonês tinha estocado aproximadamente $400 \mathrm{~kg}$ do Bacillus anthracis, agente do carbúnculo hemático e já havia desenvolvido bombas especiais de fragmentação para a dispersão desses agentes.

Em 1941, os britânicos realizaram também testes de dispersão de esporos do B. anthracis, na costa da Escócia.

Em 1943, os Estados Unidos da América iniciaram seu programa de desenvolvimento de armas biológicas. No início da década de 50, os chineses acu- 
saram inúmeras vezes os Estados Unidos do uso dessas armas. Desde então, alegações, suspeitas e eventos comprovados do uso desses agentes acumularam-se em diversas partes do mundo. Entre eles destacam-se:

- Guerra do Laos;

- Guerra do Vietnã;

- Assassinato de Georgi Markov (dissidente búlgaro) em Londres;

- Vazamento de esporos do antraz nas instalações militares russas de Sverdlovsk;

- Guerra do Afeganistão;

- Seita Rajneesh usa Salmonella. typhimurium para contaminar saladas no Texas, EUA;

- Programa de armas biológicas do Governo do Apartheid da África do Sul; - Guerra Irã-Iraque;

- Utilização pelo Iraque contra as minorias curdas;

- Tentativas de dispersão de agentes biológicos no Japão pela seita Aum Shinrikyo;

- Guerra do Golfo;

- Tentativas de aquisição de agentes biológicos por diversos grupos para militares americanos;

- Correspondências contaminadas com esporos de B. anthracis nos EUA, Quênia e Argentina.

Nas últimas duas décadas, o risco de uma guerra biológica aumentou muito. O número de países que possuem projetos nessa área é cada vez maior. Além disso, serviços de inteligência de inúmeros países têm apontado para um aumento do uso desses agentes por parte de diversos grupos terroristas e extremistas. Em 1999, o Monterrey Institute of International Studies divulgou um relatório demostrando que, somente durante aquele ano, o número de incidentes envolvendo armas de destruição em massa (nuclear, química e biológica) representavam $25 \%$ de todos os incidentes desde 1900 e $35 \%$ deles haviam ocorrido na década de 90. Dos 175 incidentes ocorridos em 1999, 104 haviam ocorrido nos EUA e 81 deles eram ameaças com $B$. anthracis.

A totalidade dos países está vulnerável ao uso de armas biológicas. O grave desequilíbrio tecnológico que se estabeleceu entre as nações nos últimos anos, provocando a perda de posição no equilíbrio do poder em inúmeras regiões do planeta, tem levado alguns países a procurar meios para recuperar e manter seu 
status geopolítico, inclusive desenvolvendo armas de destruição em massa, de baixo custo, que apresentem facilidade de serem produzidas. Sob o ponto de vista puramente econômico, a principal vantagem do emprego de armas biológicas ficou clara no painel apresentado em 1969 pelo comitê de experts das Nações Unidas, que estimou o custo de operações contra populações civis em $\$ 1 / \mathrm{Km}^{2}$ para armas biológicas, $\$ 600 / \mathrm{Km}^{2}$ para armas químicas, $\$ 800 / \mathrm{Km}^{2}$ para armas nucleares e $\$ 2000 / \mathrm{Km}^{2}$ para armamentos convencionais.

\section{Características das armas biológicas}

Parâmetros específicos tais como taxas de morbidade e mortalidade, virulência, toxicidade, inóculo inicial, período de incubação, transmissibilidade, potencial endêmico, estabilidade, características da dispersão e efeito residual estabelecem os critérios de escolha dos agentes biológicos para fins bélicos.

\section{Morbidade}

Taxa de indivíduos expostos ao agente que adoecem.

\section{Mortalidade}

Taxa de indivíduos infectados que morrem por ação do agente.

\section{Virulência}

Reflete a severidade da doença causada pelo agente. Diferentes cepas do mesmo microorganismo podem causar quadros de diferente severidade.

\section{Toxicidade}

Reflete a relativa severidade da doença causada por toxina.

\section{Inóculo Inicial}

Quantidade de microorganismos ou toxina que deve penetrar o organismo por uma determinada via para causar doença.

\section{Tempo de Incubação}

È o tempo que decorre entre a exposição e o início dos sintomas.

\section{Transmissibilidade}

Reflete a capacidade do agente em se transmitir pessoa a pessoa, de atingir os alvos individualmente ou necessitar de um vetor.

\section{Potencial Endêmico}


Reflete a capacidade do agente em ocupar um nicho ecológico, estabelecendo-se endemicamente nele.

\section{Estabilidade}

Reflete a capacidade do agente em resistir as variações do meio ambiente, incluindo temperatura, umidade relativa do ar, poluição atmosférica, luz.

\section{Características de dispersão}

Reflete a relação entre os objetivos a serem alcançados pelo uso do agente, o período desejado de permanência dele no meio ambiente e o grau de complexidade dos dispositivos de dispersão.

\section{Efeito Residual}

Reflete a capacidade do agente em permanecer no meio ambiente, ocasionando novos casos da doença.

\section{Outros fatores}

Outros fatores ainda bastante relevantes, na seleção de um agente biológico como arma, são: facilidade de produção, estabilidade de armazenamento e transporte.

\section{Classificação}

Entre os agentes passíveis de serem usados como armas biológicas, definidos pela Convenção de Proibição de Armas Biológicas como "agentes microbiológicos ou outros agentes biológicos ou toxinas, quaisquer que sejam sua origem ou método de produção, de tipos e em quantidades que não se justifiquem para fins profiláticos, de proteção ou outros fins pacíficos" incluem-se: bactérias, vírus, ricketsias e clamídeas, fungos e toxinas.

Pode-se classificar os agentes biológicos segundo sua morbidade/mortalidade como:

\section{Incapacitantes}

Com altas taxas de morbidade, levando um grande número de doentes a requerer cuidados médicos.

Ex.: Coxiella burnetii e a enterotoxina estafilocócica B.

\section{Letais}

Com altas taxas de mortalidade, ocasionando grande número de baixas letais. 
Ex.: Bacillus anthracis, Yersinia pestis, Francisela tularensis e a toxina botulínica.

\section{Dispersão}

Dispersão é o processo pelo qual microorganismos ou toxinas são distribuídos no meio ambiente afim de causar infecção e ou intoxicação.

As armas biológicas podem atingir os organismos susceptíveis (homens e animais) de diversas maneiras:

\section{Por via inalatória (através da dispersão de aerossóis)}

Microorganismos ou toxinas chegam aos alvéolos pulmonares, atingindo diretamente a corrente sangüínea.

\section{Por via oral (pela contaminação de coleções hídricas e alimentos)}

Água, alimentos e medicamentos podem se contaminar intencionalmente ou por ocasião de um ataque aerossol.

\section{Por via epidérmica (inoculação direta)}

A pele intacta não garante barreira contra a penetração de inúmeros agentes biológicos. Além disso, existem relatos de inoculação forçada com agulhas e outros instrumentos perfuro-cortantes.

\section{Através de vetores (dispersão de vetores portadores dos agentes patogênicos)}

Existem relatos da dispersão de vetores (principalmente artrópodes) para a disseminação de agentes biológicos.

Entre as formas de dispersão destaca-se, por sua simplicidade, eficácia e baixo custo a aerossolização do agente biológico que, para atingir seu objetivo, deve formar partículas entre 1 e 5 micra, capazes de permanecer suspensas por várias horas, podendo penetrar através das vias respiratórias superiores e atingir os pulmões. Partículas maiores que 5 micra são eliminadas pelos mecanismos de defesa, nas vias respiratórias superiores da maioria dos organismos susceptíveis. O clima na área-alvo é um fator também muito importante. Instabilidade meteorológica pode desfazer a nuvem formada pelo processo de aerossolização, vento estável na direção do alvo é uma condição sumamente importante para o êxito do ataque.

Estudos realizados pela OMS estimaram que $50 \mathrm{~kg}$ de esporos aerossolizados do Bacillus anthracis (agente causador do Carbúnculo Hemático ou Antraz), 
dispersos a $2 \mathrm{~km}$ de uma cidade com 500.000 habitantes (em condições meteorológicas ideais), podem se espalhar num raio de $20 \mathrm{~km}$, matando mais de 220.000 pessoas (» 50\% da população-alvo). Se Francisela tularensis (agente da Tularemia) fosse disperso, o número de mortos e incapacitados poderia chegar a 155.000 habitantes (» 35\% da população-alvo).

O potencial epidêmico/endêmico e seu conseqüente efeito residual é também importante fator da relação dispersão/eficácia do agente biológico:

Transmissão direta (pessoa-pessoa - alto potencial epidêmico)

Ex.: vírus da Varíola, Yersinia pseudotuberculosis.

Transmissão por vetores (dispersão ou presença natural de vetores competentes - alto potencial endêmico)

Ex.: Yersinia pestis/pulgas, vírus da Febre Amarela e vírus da Encefalite Eqüina/mosquitos.

\section{Contenção de um Ataque por Armas Biológicas e Saúde Pública}

Ainda não está firmemente estabelecido, entre os especialistas, como o sistema de saúde pública poderá proteger as populações de um ataque por armas biológicas. É certo que um diagnóstico clínico- laboratorial e uma rede ágil de informações epidemiológicas é imprescindível para minimizar os efeitos diretos sobre a população-alvo e o conseqüente impacto sobre os serviços de saúde, pelo rápido aumento do número de pacientes demandando cuidados intensivos, que sobrepuja os recursos médicos disponíveis, inclusive estoques de medicamentos e vacinas.

Fica claro que o número de leitos e recursos hospitalares não é suficiente para o caso de um ataque maciço, e proteção adicional é necessária para todo o pessoal médico e de laboratório, devido ao alto risco de contaminação inerente a situações dessa natureza.

Nos últimos anos, os EUA criaram o National Pharmaceutical Stockpile, um programa estratégico de estoque e distribuição emergencial de antibióticos e recursos médicos. Naturalmente, ainda não foi testado em tempos de crise.

Baseado em todos esses fatores, até recentemente, nos EUA, permanecia uma incógnita: se os médicos seriam capazes de diagnosticar, inequivocamente, doenças há muito tempo esquecidas. Por exemplo, lá não ocorrem casos de Carbúnculo/Antraz há mais de 20 anos. No Brasil, segundo a Fundação Nacional de Saúde, não há casos humanos recentemente relatados. Em pesquisa realizada entre médicos de diversos hospitais, ficou clara a ausência de conhecimen- 
to para a realização do diagnóstico e o estabelecimento da terapia dessa doença. Em outros países da América Latina, casos de Antraz ainda ocorrem, principalmente entre profissionais de saúde animal e manejo de gado bovino e ovino.

Neste quadro, as medidas médicas de proteção da população em geral, dos profissionais de saúde, das equipes de segurança e de todo o pessoal militar envolvido em um ataque com armas biológicas, variam segundo o risco ou seu uso confirmado e segundo a exposição confirmada sem sintomas ou na vigência de sinais e sintomas.

Antes da exposição, vacinação e ou antibioticoprofilaxia podem prevenir o aparecimento de doença, sendo efetivas contra a maioria dos agentes biológicos conhecidos. São provavelmente as melhores modalidades de proteção das unidades de combate contra uma ampla variedade de microorganismos patogênicos.

Após a exposição, vacinação, imunoglobulinas, terapia antibiótica e antiviral podem aliviar sintomas e reduzir a mortalidade.

Após a exposição, no curso de doença ativa, somente um diagnóstico rápido e preciso, seguido de uma terapia específica e de suporte, pode evitar uma grande maioria de êxitos letais.

Impacto Econômico de um Ataque com Armas Biológicas

$\mathrm{O}$ impacto de um ataque com armas biológicas depende:

- da natureza do agente utilizado;

- do método e da eficiência da dispersão deste agente;

- do nível de imunidade da população-alvo;

- da disponibilidade e da eficiência dos programas pós-exposição de profilaxia e terapia;

- do potencial de transmissão direta (pessoa a pessoa).

Compreender e quantificar o impacto de um ataque com armas biológicas é primordial para desenvolver um efetivo plano de contenção. É da análise de inúmeros fatores, inclusive econômicos, que se pode estabelecer um programa de intervenção pós-ataque:

\section{Perdas na força de trabalho}

O custo das perdas na força de trabalho e dos salários não pagos, decorrentes das mortes prematuras e do período de internação hospitalar, distribuídas por idade e sexo.

\section{Hospitalização}

Todos os custos com os serviços profissionais, medicamentos e exames 


\section{Valdi Tutunji}

complementares de laboratório e imagem.

\section{Medidas de Contenção}

Custo dos antimicrobianos e vacinas usados no programa de profilaxia e dos procedimentos de descontaminação de ambientes e objetos.

\section{Manutenção de Programas Preventivos e de Contingência}

Custos de manutenção dos estoques estratégicos de medicamentos, vacinas e outros recursos médicos.

\section{Treinamento e Manutenção de Equipes Especializadas}

Custos de treinamento, manutenção e disponibilização de pessoal civil e militar com capacidade de rapidamente identificar o agente, descontaminar ambientes, distribuir medicamentos e outros recursos, tratar pacientes e manter a ordem na população.

\section{Inteligência}

Custos de manutenção de serviços de inteligência capazes de, antecipando os riscos de um ataque, reduzir a probabilidade de perdas maiores. Há um consenso de que o aumento da vigilância, apesar de não garantir segurança absoluta, pode reduzir o êxito do ataque.

Um percentual significativo de perdas esperadas pode ser minimizado pela capacidade do plano de contenção responder ao ataque o mais rapidamente possível, reduzindo o número de indivíduos expostos, de doentes, de hospitalizações e de mortes. Assim, para doenças com curto período de incubação, como o Carbúnculo/Antraz e a Tularemia, esses programas devem ser instituídos até 72 horas após a exposição. A eficácia de um programa de contenção é medida pelas taxas de morbidade e mortalidade pós-exposição.

Devido às diferentes taxas de morbidade e mortalidade, um ataque pelo $B$. anthracis causa mais prejuízos que um ataque com $F$. tularensis ou B. melitensis. Se um programa de profilaxia é iniciado prontamente, o impacto econômico do ataque por estes microorganismos é reduzido bastante, devido ao alto custo das drogas e dos procedimentos de hospitalização inerentes ao tratamento.

Comparativamente, as perdas econômicas ocasionadas por um ataque com armas biológicas podem variar de $\$ 448$ milhões (em um cenário com $B$. melitensis) a $\$ 26$ bilhões (em um cenário com pelo $B$. anthracis), para cada 100.000 pessoas expostas.

A capacidade de rapidamente identificar pessoas em risco apresenta grande impacto sobre o custo total da contenção de um ataque por armas biológicas; 
todavia, atraso na implementação de um programa de profilaxia é o fator mais importante no aumento global das perdas. A velocidade com que um plano de contenção pós-ataque, inclusive profilaxia, for efetivamente implementado é crítica para seu sucesso.

\section{Bioterrorismo}

Nossos conhecimentos sobre o terrorismo têm sido desafiados todos os dias. Os acontecimentos que se seguiram a 11 de setembro de 2001 têm demonstrado a necessidade de atualização urgente de conceitos e políticas, desenvolvidas e estabelecidas há pelo menos 25 anos, durante a guerra fria, quando existia uma dinâmica internacional muito diferente da atual.

O terrorismo hoje, baseado em imperativos religiosos, diferente do terrorismo do passado, de cunho etno-separatista, nacionalista e ideológico, apresenta novas motivações e justificativas. Tudo isso, aliado aos avanços tecnológicos das últimas décadas, aumentou a capacidade de ação dos grupos terroristas.

Para entender as motivações que levam uma organização terrorista a utilizar uma arma biológica é necessário avaliar a percepção de risco que as autoridades e a população em geral têm. Parte desse problema está relacionado ao conceito, amplamente disseminado, de que as armas biológicas são dispositivos de destruição em massa. Isto leva a algumas observações:

- O termo destruição em massa que reúne os agentes e dispositivos nucleares, químicos e biológicos em uma só classe de armas, tem impedido o efetivo reconhecimento dos riscos e peculiaridades de cada uma delas individualmente.

- O pânico decorrente da percepção do risco por parte da população é um componente importante na disseminação de conceitos equivocados acerca do eventual agente biológico utilizado no ataque.

- Os recentes acontecimentos deixaram na população uma noção de que as autoridades e os mecanismos de prevenção e contenção a um ataque com armas biológicas não são eficientes tanto quanto se esperava.

- Pequena quantidade de um determinado agente biológico, sendo capaz de produzir grande número de baixas, gera conseqüentes políticas de contenção (prevenção, atendimento de emergência, logística), em um amplo leque de conseqüências, que obscurece qualquer explanação racional dos motivos do ataque.

Historicamente, o bioterrorismo tem sido praticado há muito tempo para sabotagem e assassinatos políticos. Esse uso permaneceu restrito, no entanto, devido ao difícil acesso a microorganismos potencialmente eficazes como arma e ao pequeno número de pessoas com conhecimento técnico para utilizá-los. Mas isso 
mudou. Novos conhecimentos, relacionados à microbiologia, epidemiologia e biotecnologia vieram facilitar o desenvolvimento dessas armas. No entanto, devemos ainda fazer uma clara distinção entre:

\section{Terrorismo utilizando agentes biológicos como arma}

Usa quaisquer agentes biológicos patogênicos, presentes no meio ambiente ou em outras fontes naturais, isolados por meio de técnicas microbiológicas rotineiras.

Ex.: S. typhimurium utilizada pela seita religiosa Rajneesh para contaminar saladas nos EUA, facilmente isolados de amostras de fezes humanas ou animais e esgotos.

\section{Terrorismo utilizando armas biológicas propriamente ditas}

Usa agentes biológicos desenvolvidos e selecionados para uso militar ofensivo, adquiridos no mercado negro, remanescentes de programas de armas biológicas de inúmeros países ou desenvolvidos, em pequena escala, de maneira artesanal.

Ex.: Gás sarin utilizado pela seita Aum Shinrikyo no metrô de Tóquio.

Observadas as recentes reações das autoridades e da população em geral, guardadas as devidas proporções entre os ataques com estas duas classes de armas biológicas, em que pese a maior estabilidade e eficácia dos agentes desenvolvidos para uso militar, seu principal objetivo, enquanto armas capazes de ocasionar grande número de baixas, é instituir um ambiente de pânico em larga escala, pela percepção do risco de exposição a agentes virtualmente insípidos, inodoros, incolores e invisíveis.

\section{Convenção de armas biológicas}

Desde a Convenção de Haia (1907) que proíbe o emprego de venenos e armas envenenadas, da Convenção de Washington (1922) que repudia o uso de gazes asfixiantes e substâncias venenosas, da Convenção de Genebra (1925) que proíbe o uso de armas bacteriológicas, confirmada pela Conferência Mundial de Desarmamento em 1932, a comunidade das nações tem tentado, em vão, impor o preceito de não proliferação de armas.

Após o término da II Guerra Mundial, nem o Congresso Internacional de Microbiologia (1947), nem a Conferência de Genebra (1949) lograram avanços e resultados satisfatórios.

Os Estados Unidos que, em 1941, iniciam seu programa de armas biológicas em Fort Detrick, Maryland e, em 1943, estabelecem um campo de testes no 
Mississipi, anunciam em 1946 que vêm realizando pesquisa com armas biológicas. Com a inauguração, no Arkansas, de novas instalações que permitem a produção de armas biológicas em maior escala, ampliam as pesquisas para o desenvolvimento de diversos agentes biológicos e dispositivos de dispersão.

Todavia, em 25 de dezembro de 1969, durante o governo Nixon, os EUA renunciam unilateralmente à pesquisa, desenvolvimento e produção de armas biológicas, inclusive toxinas. Entre 1971 e 1972, os estoques de armas biológicas americanos são, então, destruídos. Nesses estoques constavam cepas de Bacillus anthracis, Coxiella burnetii, Francisela tularensis, Brucella suis, vírus da Encefalite Eqüina, toxina botulínica e enterotoxina B estafilocócica.

Em 1972, abre-se à assinatura a Convention on the Prohibition of the Development, Production and Stockpiling of Bacteriological Biological and Toxin Weapons and on Their Destruction (Convenção sobre a Proibição do Desenvolvimento, Produção e Estocagem de Armas Bacteriológicas Biológicas e à base de Toxinas e sua Destruição). A Convenção de Armas Biológicas, como se convencionou chamar, pró́be o desenvolvimento, a produção, o armazenamento e a aquisição de agentes biológicos ou toxinas, em quantidades e tipos que não se justifiquem para usos profiláticos, defensivos ou outros propósitos pacíficos. Foi aberta à assinatura em abril daquele ano, com os Estados Unidos, a Inglaterra e a então União das Repúblicas Socialistas Soviéticas como depositários da Convenção. Até o momento os estados signatários são: Afeganistão, África do Sul, Albânia, Alemanha, Arábia Saudita, Argentina, Armênia, Austrália, Áustria, Bahamas, Bahrain, Bangladesh, Barbados, Belarus, Bélgica, Belize, Benin, Butão, Bolívia, Bósnia Herzegovina, Botswana, Brasil, Brunei Darussalam, Bulgária, Burkina Faso, Camboja, Canadá, Cabo Verde, Chile, China, Colômbia, Congo, Coréia do Sul, Coréia do Norte, Costa Rica, Croácia, Cuba, Chipre, Dinamarca, Equador, El Salvador, Eslováquia, Eslovênia, Espanha, Estados Unidos, Etiópia, Estônia, Guiné Equatorial, Federação Russa, Fidji, Filipinas, Finlândia, França, Gâmbia, Gana, Geórgia, Granada, Grécia, Guatemala, Guiné-Bissau, Honduras, Hungria, Ilhas Salomão, Índia, Indonésia, Irã, Iraque, Irlanda, Islândia, Itália, Iugoslávia, Jamaica, Japão, Jordânia, Kuwait, Laos, Letônia, Líbano, Lesoto, Líbia, Liechtenstein, Lituânia, Luxemburgo, Macedônia, Malásia, Maldivas, Malta, Maurício, México, Mônaco, Mongólia, Nova Zelândia, Nicarágua, Nigéria, Noruega, Oman, Países Baixos, Paquistão, Panamá, Papua Nova Guiné, Paraguai, Peru, Polônia, Portugal, Qatar, Quênia, Quirguistão, República Dominicana, Reino Unido, República Tcheca, Romênia, Ruanda, São Cristóvão e Nevis, Santa Lúcia, São Vicente e Granadinas, San Marino, São Tomé e Príncipe, Senegal, SérviaMontenegro, Seichelles, Serra Leoa, Singapura, Sri Lanka, Suriname, Suazilândia, Suécia, Suíça, Tailândia, Togo, Tonga, Tunísia, Turcomenistão, Turquia, Ucrânia, 


\section{Valdi Tutunji}

Uganda, Uruguai, Uzbequistão, Vanuatu, Venezuela, Vietnã, Yêmen, Zaire e Zimbabwe, dos quais ainda não ratificaram o instrumento: Burundi, Costa do Marfim, Egito, Emirados Árabes Unidos, Gabão, Guiana, Haiti, Libéria, Madagascar, Mali, Malawi, Marrocos, Myanmar, Nepal, República Centro-Africana, Síria, Somália e Tanzânia.

Em 5 de dezembro de 1972, o Brasil aprovou no Senado Federal, por meio do Decreto Legislativo ${ }^{\circ}$ 89, o texto da Convenção (anexo I). Em 1 de abril de 1976, o então Presidente da República, Ernesto Geisel, assinou o Decreto no 77.734 que promulgou a Convenção, ratificando-a.

\section{Inteligência}

Relatos dos serviços de inteligência de diversos países relacionam programas de pesquisa médica e atividades militares em diversos países. Muitos desses relatórios indicam que a proliferação dessas armas é muito grande, conforme temos observado, pelo uso desses agentes por parte de diversos grupos terroristas.

Entre os principais países citados encontram-se:

\section{China}

A China é membro da Convenção de Armas Biológicas desde 1984. Acredita-se que tenha mantido um programa de armas biológicas ofensivas por toda a década de 80 , que incluía desenvolvimento, produção, estoque, aquisição e manutenção de agentes biológicos com fins militares. Órgãos da inteligência americana acreditam que a China pode ter reativado e possivelmente expandido seu programa de armas biológicas, nos últimos anos. Esta crença baseia-se no fato de que dois centros de pesquisa biológica, nitidamente civis, apresentam-se sob controle militar. Estes centros de pesquisa são conhecidos por terem estado previamente envolvidos na produção e armazenamento de armas biológicas. Recentemente, um desses centros foi expandido. Informações fornecidas pelo governo chinês com o propósito de estabelecer medidas de confiança não foram capazes de convencer os órgãos de inteligência norte-americanos e são fortes indícios, segundo estes órgãos, de que a China mantém ainda um programa de armas biológicas ofensivas.

\section{Egito}

O Egito é signatário, mas não membro, da convenção de armas biológicas e tem um programa de pesquisa militar aplicada na área de armas biológicas, desde 1960. Em 1970, o então Presidente egípcio Anwar Sadat confirmou a existência de agentes biológicos em instalações egípcias refrigeradas subterrâneas. O Egito 
tem estudado várias toxinas, técnicas de produção e refino. Nenhuma informação até a presente data indica que os egípcios tenham produzido seus próprios agentes biológicos. Pesquisadores egípcios têm cooperado com unidades militares e laboratórios civis norte-americanos em áreas relacionadas à defesa biológica, especificamente relacionadas com microorganismos altamente patogênicos e vetores. A marinha norte-americana mantém em território egípcio um laboratório médico-militar com objetivo declarado de pesquisa na área de defesa contra agentes de doenças infecciosas. Este laboratório é reconhecido como um centro regional de referência, aparelhado com equipamentos de última geração e equipe norte-americana altamente qualificada. Pesquisas desenvolvidas por esse laboratório são secretas. A opinião geral é de que o Egito apresenta capacidade de manter e desenvolver um programa de guerra biológica.

\section{Ir $\tilde{a}$}

O Irã, que se juntou à Convenção de Armas Químicas em 3 de novembro de 1997 e é membro da Convenção de Armas Biológicas desde 1973, tem infra-estrutura técnica para manter um significativo programa de guerra biológica. Já foram relatadas diversas tentativas, por parte das autoridades iranianas, de comprar não oficialmente tecnologia e materiais usados especificamente na produção de armas biológicas, em particular, micotoxinas. O Irã conduz ainda legítimas pesquisas biomédicas em diversos institutos suspeitos de envolvimento em programas de guerra biológica. O governo iraniano não forneceu ainda à ONU qualquer medida de construção de confiança em relação a suas atividades biotecnológicas. As forças armadas iranianas têm usado organizações médicas, educacionais e de pesquisa científica em muitos aspectos da pesquisa e produção de agentes biológicos. Diversas informações indicam que o Irã provavelmente produz agentes biológicos e, aparentemente, tem pequena quantidade desses agentes para uso militar.

\section{Israel}

Apesar das muitas publicações associadas com armas de destruição em massa, as forças armadas de Israel ainda não se declararam oficialmente sobre um programa de desenvolvimento de armas biológicas. Tal programa, possivelmente espelhado nos antigos programas americano e soviético, deve provavelmente envolver os seguintes agentes biológicos: $B$. anthracis, $C$. botulinum, F. tularensis, Y. pestis, Vírus da Encefalite Eqüina Venezuelana e Coxiella burnetti. Similarmente, os sistemas israelenses de dispersão desses agentes devem reproduzir os desenvolvidos pelos EUA, a saber: sistemas pulverizadores e submunição equipada em mísseis. Israel é um de poucos estados que não assinou a Convenção de Armas Biológicas. 


\section{Líbia}

Muito já foi especulado sobre o programa de armas químicas da Líbia, particularmente sobre as instalações industriais farmacêuticas em Rabta e o abrigo subterrâneo em Tarhunah. Embora se acredite que a Líbia tenha tentado desenvolver um programa de armas biológicas, pouco se sabe de informações concretas sobre o programa. Membro da Convenção de Armas Biológicas desde 1972, há informações que indicam a realização de testes iniciais de desenvolvimento e dispersão. Presentemente, a Líbia tem expressado seu interesse nos programas de pesquisa de diversos países. Estabelecendo contato com representantes de outros países árabes, indicou sua vontade de financiar programas de pesquisa, incluindo os de natureza militar, desde que não sejam empreendidos em território líbio. A Líbia também não submeteu até hoje uma declaração formal de medidas de construção de confiança a uma apreciação por parte das Nações Unidas. De acordo com uma avaliação dos EUA, a Líbia está procurando adquirir a capacidade para desenvolver e produzir agentes biológicos.

\section{Coréia do Norte}

A Coréia do Norte, membro da Convenção de Armas Biológicas desde 1987, é uma das sociedades mais fechadas e pesadamente militarizadas do planeta. Durante a década de 60 iniciou programa de armas biológicas ofensivas. Atualmente, desenvolve pesquisa militar-biológica em universidades, institutos médicos e centros de pesquisa especializados, envolvendo diversos patógenos: $B$ anthracis, $V$. cholerae e $Y$. pestis. Há evidências que indicam que realizaram teste de armas biológicas em seus territórios insulares.

\section{Síria}

A Síria assinou, mas não ratificou, a Convenção de Armas Biológicas. Israel afirma que a Síria tem agentes biológicos para contaminar fontes de água potável; entretanto nenhuma informação confirma a existência dessas armas. Não há confirmação de um programa sírio dirigido para o desenvolvimento de potencial ofensivo com armas biológicas. Todavia, a Síria permanece entre aqueles países que os EUA acreditam desenvolver programas de guerra biológica.

\section{Taiwan}

Taiwan, que se juntou à Convenção de Armas Biológicas em 1973, é outro país suspeito de desenvolver armas químicas e biológicas e, apesar de declarar formalmente não possuir armas dessa natureza, tem apresentado interesse em conduzir pesquisa biológica de natureza militar. Taiwan tem uma base científica e técnica significativa em microbiologia, com grande número de especialistas hábeis em biotecnologia, em sua maioria formados nos EUA e Europa ocidental. 
Recentemente tem promovido seu setor de biotecnologia, que faz largo uso de técnicas básicas, imprescindíveis à produção de armas biológicas. Taiwan participa internacionalmente na cooperação científica, técnica e industrial em pesquisa biológica juntamente com EUA, Japão, França e outros países ocidentais. Vários programas biomédicos comuns estão em andamento em áreas como: imunologia, engenharia genética e medicina tropical. Os centros biológicos militares de Taiwan treinam pessoal em especialidades médicas e biológicas. Há evidência suficiente para afirmar que Taiwan ainda não produz armas biológicas, mas as pesquisas científicas e a base industrial avançada podem permitir ao país produzir armas biológicas com facilidade relativa.

\section{O Grupo da Austrália}

O Grupo de Austrália, nascido em 1984, é um arranjo informal, composto inicialmente por 28 países industriais, que visa impedir a propagação de materiais e da tecnologias relacionadas ao desenvolvimento e a produção de armas químicas e biológicas.

O grupo é um fórum para troca de informações e formação de consenso, preparando listas de precursores químicos, microorganismos, tecnologias e equipamentos, para que os países membros possam orientar seu licenciamento industrial e de exportação, afim de impedir a proliferação de armas dessa natureza.

Presentemente, 30 países fazem parte do Grupo da Austrália: Argentina, Austrália, Áustria, Bélgica, Canadá, República Tcheca, Dinamarca, Finlândia, França, Alemanha, Grécia, Hungria, Islândia, Irlanda, Itália, Japão, Luxemburgo, Países Baixos, Nova Zelândia, Noruega, Polônia, Portugal, Romênia, República Eslováquia, Coréia do Sul, Espanha, Suécia, Suíça, Reino Unido, Estados Unidos e uma comissão da União Européia (como observador). Pedidos para outros estados juntarem-se ao grupo são analisados individualmente.

Em 10 de dezembro de 1992, o Grupo publicou um primeiro documento relacionando suas atividades, estabelecendo normas de exportação para determinados microorganismos, toxinas (anexo III) e equipamentos (anexo II) que poderiam ser utilizados em programas de armas biológicas. Periodicamente publica uma lista de advertência onde relaciona microorganismos, toxinas e tecnologias, alertando os países membros e incentivando a indústria, a comunidade científica e outros grupos relevantes a relatarem quaisquer transações suspeitas que ofereçam riscos para a proliferação dessas armas (anexos IV). 


\section{O Quadro Político e Estratégico Mundial}

À luz dos últimos acontecimentos mundiais, ficou bem claro que nossa confiança nas atuais estratégias de combate, prevenção e contenção a um possível ataque com armas biológicas não são efetivas tanto quanto se desejaria. Os casos recentes de Carbúnculo/Antraz indicam que não se deve esperar amplos ataques como prenunciavam inúmeros relatórios de especialistas do mundo inteiro. O principal objetivo de uma arma biológica é instaurar o pânico na população-alvo. Isto os casos recentes já conseguiram. Fica claro que ações isoladas, executadas individualmente para contaminar ambientes restritos ou grupos selecionados, ocasionando poucos casos da doença, têm enorme efeito moral sobre a população. Grande número de americanos têm buscado seus médicos procurando adquirir receitas de antibióticos para estocar em suas casas, ao sabor do noticiário veiculado no dia anterior. Há 50 anos nos EUA estocava-se água, alimentos e pequenos utensílios para prevenir os efeitos de possíveis ataques nucleares pela URSS. Hoje, os americanos estão estocando antibióticos e máscaras contra gases. O medo de um ataque com armas biológicas beira o pânico em boa parte dos EUA.

O eixo norteador de esforços que possam conter a corrida para desenvolver e adquirir a tecnologia de armas biológicas permanece sendo um tratado global que consiga banir definitivamente estas armas.

Negociações para eliminar armas químicas e biológicas datam do início do século XX. Sem grandes avanços desde então, somente em 1968, no auge da Guerra Fria, aproveitando o ensejo do Tratado de Não-Proliferação de Armas Nucleares, as Nações Unidas retornaram ao tema. Com a decisão dos EUA de unilateralmente renunciar ao emprego ofensivo de armas biológicas e a conseqüente destruição de seus estoques de agentes biológicos, um acordo bilateral com a então URSS foi rapidamente concluído. Este acordo serviu de base para o estabelecimento, em 1972, de um acordo multilateral, a Convenção de Armas Biológicas.

Desde a primeira revisão prevista para 1980, a Convenção de Armas Biológicas suscitou dúvidas quanto a sua eficácia, em especial após o acidente em Sverdlovsk (URSS) em 1979, que viria levantar suspeitas sobre o cumprimento do acordo pelos países signatários. Durante a década de 90, com a Guerra do Golfo, ficou clara a necessidade de fortalecimento da convenção, quando um grupo de trabalho ad hoc, composto por especialistas dos diversos Estados-parte, foi instituído para elaborar um protocolo de monitoramento e inspeção.

Com o início do Século XXI, diversos Estados pode-se já observar uma evolução na natureza do problema das armas biológicas. Novas tecnologias propor- 
cionaram o aparecimento de novos atores, alguns inclusive não nacionais, criando renovadas possibilidades e questionando a viabilidade e a eficácia dos atuais tradicionais mecanismos mundiais de controle de armas. Os esforços para reforçar esses mecanismos têm esbarrado em inúmeros obstáculos:

- Como cada ação de verificação deverá ser conduzida, baseada no estado da arte, de maneira a obter informações relevantes, com alto grau de confiança, afim de detectar atividades proscritas pela convenção.

- Como uma verificação poderá ser eficaz, sem expor informações industriais proprietárias, especialmente em áreas vitais como biotecnologia e biologia molecular.

- Como "facilitar o mais amplo intercâmbio de equipamento, materiais e informação científica e tecnológica para uso de agentes bacteriológicos (biológicos) e toxinas para fins pacíficos", sem "transferir a quem quer que seja, direta ou indiretamente (...) quaisquer agentes, toxinas, armas, equipamentos ou vetores", coordenando as decisões dos art. III e X da Convenção de Armas Biológicas.

Todas essas dúvidas demonstram falta de consenso em questões vitais. Cedo ou tarde, no entanto, a conclusão do protocolo é certa, o que deverá requerer ainda a assinatura pelos Estados parte e sua ratificação, criando novas obrigações. Este processo, por si só demorado, poderá sofrer grandes atrasos, se interesses comerciais sobrepuserem-se aos interesses da segurança e da paz. Ao que tudo indica, um regime ambíguo em que alguns Estados-parte aceitam inspeções, e outros não, deverá prevalecer por longo tempo. Demonstrações de incapacidade e ou falta de interesse em fazer cumprir as determinações levarão a flagrantes violações e devem ser evitadas, considerando-as tão importantes para a viabilidade da Convenção, quanto criar e aperfeiçoar novos mecanismos de monitoramento.

Desde sua criação, uma série de Conferências de Revisão foram realizadas na tentativa de estimular e negociar medidas voluntárias de construção de confiança, mas apenas uma pequena parcela de Estados-parte tem participado. Assim, a necessidade de estabelecer medidas de acompanhamento do cumprimento das determinações da Convenção, sob um ponto de vista científico e técnico, levou à criação, em setembro de 1994, do Grupo ad hoc de Trabalho, que vem desde então elaborando um protocolo de monitoramento e inspeção.

Passados seis anos, o Grupo, reunido periodicamente em Genebra, produziu um rascunho com mais de 300 páginas. Embora algum progresso tenha sido feito, muitos termos e parágrafos permanecem sem consenso. Com muitos trechos técnicos, grande parte do rascunho reflete discordância em base filosófica 
de qual seria a melhor maneira de implementar inspeções in situ. Os Estados Unidos, por exemplo, protegendo os interesses da indústria farmacêutica, não concordam com a proposta de inspeções aleatórias de instalações industriais. Os Estados não alinhados, por outro lado, têm condicionado seu apoio ao documento a um desmantelamento dos controles de transferência de tecnologia, principalmente equipamentos e materiais de biotecnologia, entre os Estados-parte.

A falha do Grupo ad hoc de Trabalho em concluir as negociações pode significar uma desaceleração ou uma indefinida suspensão das conversações. A falta de habilidade em concluir o protocolo poderá soar como complacência ou apatia em relação ao problema, resultando num rápido aumento de países dispostos a desenvolver programas de armas biológicas. Os atuais possuidores dessa tecnologia podem sentir-se compelidos a ampliar seus arsenais, aumentando do risco do uso dessas armas por atores não nacionais.

Nos EUA, existe uma corrente para abandonar as negociações ou, ao menos, não lhes dar tanta importância, atuando unilateralmente com políticas que impeçam a proliferação de armas biológicas, como controle de exportação e medidas contra instalações e países com programas de desenvolvimento suspeitos. Esta posição, baseada em ações unilaterais pode ser contraproducente, uma política de ações contra instalações suspeitas de possuírem ou desenvolverem armas biológicas, pode inibir as iniciativas de construção de confiança, ainda não consolidadas, que décadas de trabalho estabeleceram, incentivando por fim, o uso dessas armas como forma de retaliação.

O bloqueio por meio do controle de exportações também não parece eficaz para prevenir a difusão e o intercâmbio de agentes biológicos, tecnologia e equipamentos, devido a seu uso intrínseco relacionado ao desenvolvimento e pesquisa biomédica. A melhor maneira de diminuir o risco do uso de armas biológicas é modificar a disposição dos países suspeitos de possuí-la, reforçando a norma internacional e reduzindo sua utilidade militar. Estes objetivos podem ser alcançados pelo efetivo cumprimento das determinações da Convenção, aliado a sanções econômicas e políticas, no âmbito das Nações Unidas, aplicadas aos países que se dispuserem a descumpri-las.

\section{Conclusão}

O controle de armas biológicas deve, pois, traduzir-se em um esforço conjunto, que faça parte de uma estratégia global, integrando vários atores capazes de entender e apontar soluções para o problema:

- Um Conselho da Segurança mais representativo, disposto e capaz de cumprir suas responsabilidades como um fator do regime global de controle de armas, 
garantindo a segurança de Estados membros das Nações Unidas.

- Funcionamento eficaz dos dispositivos globais de controle de armas (Convenção de Armas Químicas, Convenção de Armas Biológicas, Tratado de Não Proliferação de Armas Nucleares), estendendo seus efeitos sinergicamente entre si e a inúmeros acordos regionais, permitindo maior transparência no cumprimento das determinações, aumentando a confiança nestes dispositivos multilaterais e diminuindo os interesses e necessidades de segurança de cada país.

- Um regime de controle eficaz para o licenciamento e a exportação de materiais e para a transferência de tecnologias, sensíveis sob o ponto de vista da Convenção de Armas Biológicas.

- Ajuda técnica e militar (capacidade de prevenção, contenção e contramedidas, defesa ativa e passiva) para aqueles países que enfrentam risco de ataque biológico. Sem esta ajuda, um ataque com armas biológicas pode resultar em resposta com armas nucleares que teria conseqüências desastrosas para os tratados globais de não proliferação de armas.

- Aumento da capacidade antiterrorista, abrangendo inteligência, prevenção, contenção e contramedidas. Sem estas medidas, é possível que o uso de armas biológicas se torne uma modalidade habitual de ataque por parte de atores não-nacionais, tais como terroristas, pelo crime organizado e o narcotráfico.

\section{Verificando o cumprimento da Convenção de Armas Biológicas}

Para impedir que as negociações no âmbito da Convenção falhem, é necessário:

\section{Intensificar as negociações}

As negociações do Grupo ad hoc de Trabalho deverão ser intensificadas e concluídas.

\section{Trabalhar para que uma versão do protocolo seja disponibilizada rapida- mente}

Intensificar negociações para eliminar as expressões, frases e palavras ainda sem consenso, de maneira a produzir uma versão brevemente.

Se as negociações do protocolo atrasarem ou falharem, uma versão concisa deve ser negociada de maneira a prevenir o colapso das conversações, construindo os alicerces para futuras negociações, ajudando a reforçar a Convenção e contemplando elementos básicos que a maioria das delegações acreditam ser indispensáveis para a construção da confiança entre os Estados-parte, tais como: 


\section{Investigação de epidemias suspeitas}

Se uma epidemia de doença infecciosa parecer suspeita em sua origem, um Estado-parte poderá solicitar uma investigação. A equipe de investigação deverá ter acesso garantido à área afetada, incluindo o direito de entrevistar vítimas e equipe médica, recolher amostras biomédicas e ambientais.

\section{Declaração obrigatória de instalações}

Todos os Estados-parte deverão declarar suas instalações de biodefesa, laboratórios de pesquisa microbiológica com altos níveis de biossegurança, instalações governamentais e industriais que contenham microorganismos, seus produtos e equipamentos ou detenham tecnologias capazes de desenvolver, produzir e estocar agentes biológicos em larga escala.

\section{Visitas voluntárias de inspeção}

Qualquer Estado-parte poderá solicitar inspeção para elucidar dúvidas sobre as declarações obrigatórias de instalações de outro país. Esta visita de inspeção às instalações declaradas deverá ter caráter voluntário por parte do país solicitado.

\section{Equipe técnica de inspeção}

Uma equipe técnica de inspeção deverá ser instituída para conduzir as investigações a campo, inclusive visitas voluntárias de inspeção, e analisar as declarações obrigatórias de instalações.

\section{Futuras negociações}

Em uma segunda fase de negociações, inspeções aleatórias de desafio em instalações declaradas e não declaradas devem ser negociadas.

\section{Outras Medidas}

Algumas outras iniciativas pertinentes, no âmbito da ONU, também devem ser implementadas:

\section{Desenvolver, ampliar e aperfeiçoar os sistemas mundiais de vigilância epidemiológica}

A OMS deverá ser capaz de manter um mais efetivo sistema de vigilância epidemiológica global, monitorando epidemias, detectando possíveis usos de armas biológicas, conseqüentemente dificultando seu uso e ampliando a capacidade de contenção e contramedidas. 


\section{Controle e regulamentação do comércio de microorganismos}

Negociação de normas internacionais de comércio de microorganismos, que deverão ser exclusivos para pesquisas biomédicas legítimas. Vendedores e compradores de agentes microbiológicos deverão sofrer periódica inspeção pela OMS ou por algum outro organismo internacional. Transações, inclusive não comerciais, envolvendo microorganismos e seus produtos, deverão ser cuidadosamente investigadas, de maneira a impedir transações ilícitas.

Criação de um tratado de criminalização de posse e uso de armas químicas e biológicas

O rascunho de um tratado nesse âmbito já existe e vem sendo proposto, com poderes de julgamento e extradição de indivíduos portadores de armas químicas e biológicas.

Criação de um organismo internacional de estudos sobre armas químicas $e$ biológicas

Um organismo no âmbito da ONU que receba, compile, traduza e distribua as declarações voluntárias de construção de confiança, o que facilitaria o intercâmbio entre os Estados-parte da Convenção, provendo um fórum de discussão, servindo como núcleo de um organismo de controle do uso dessas armas.

\section{Iniciativas em Âmbito Nacional}

Em âmbito nacional, algumas medidas se fazem necessárias para estabelecer um clima de segurança, pela diminuição da percepção de risco por parte das autoridades e da população em geral. Do contrário, pode ter consequiências danosas a implementação de qualquer plano de contenção a um eventual ataque com armas biológicas:

Estabelecer uma política nacional de prevenção, contenção e contramedidas

Criar e desenvolver um programa nacional de defesa biológica, contemplando ações civis e militares de prevenção, contenção e contramedida.

Aumentar a capacidade de prevenção, contenção e contramedidas das Forças Armadas

Aumentar a capacidade de prevenção, contenção e contramedidas das unidades militares nacionais, em cenários defensivos ou ofensivos. 


\section{Prevenir do uso de armas biológicas pelo crime organizado e pelo narcotráfico}

Criar e aprimorar dispositivos legais contra a aquisição, posse e uso de armas biológicas, reforçando a norma legal, prevenindo o risco do uso dessas armas por grupos terroristas e pelo narcotráfico.

\section{Estabelecer uma ampla rede nacional de vigilância epidemiológica}

Aperfeiçoar os atuais sistemas de vigilância epidemiológica e inteligência em saúde, estabelecendo uma rede ágil de informações que permita o reconhecimento de casos isolados e epidemias em tempo real por todo o território nacional.

\section{Estabelecer uma política nacional de inspeção às instalações industriais biomédicas e farmacêuticas}

Aperfeiçoar os atuais sistemas de vigilância sanitária e licenciamento de processos industriais relacionados à fabricação de produtos biomédicos e farmacêuticos, principalmente os que envolvam biotecnologia e biologia molecular.

Iniciar negociações bilaterais para o desenvolvimento de programas de cooperação

Criar iniciativas bilaterais para o desenvolvimento de programas de cooperação mútua para a aplicação de contramedidas, prevenção e contenção de ataques com armas biológicas, intercâmbio de agentes biológicos, equipamentos e tecnologias relacionadas.

Assumir rigorosamente as responsabilidades frente aos tratados de não proliferação de armas

Cumprir as determinações dos tratados de não proliferação de armas (Convenção de Armas Químicas, Convenção de Armas Biológicas, Tratado de Não Proliferação de Armas Nucleares) rigorosamente, para reforçar sua posição de país não beligerante frente à comunidade internacional.

\section{Assumir posição de liderança entre os países que não possuem capacidade} biotecnológica e industrial

Aproveitar a posição de país não beligerante para criar uma frente de pressão ampla, reunindo os países que não possuem grande capacidade biotecnológica e industrial, fazendo estabelecer uma política mundial de não proliferação de armas.

Talvez por pura ignorância de seus verdadeiros riscos, havia até recentemente uma noção largamente aceita de não dar a devida importância ao proble- 
ma das armas biológicas; contudo, parafraseando Manuel Castells: "Estamos em guerra. Achei que o mais honesto era revelar em que consiste essa guerra. Oxalá eu esteja enganado".

\section{ANEXO I \\ CONVENÇÃO SOBREA PROIBIÇÃO DO DESENVOLVIMENTO, PRODUÇÃO E ESTOCAGEM DEARMAS BACTERIOLÓGICAS (BIOLÓGI- CAS) E À BASE DE TOXINAS E SUA DESTRUIÇÃO}

\section{Os Estados-parte nesta Convenção,}

Decididos a agir para obter progresso efetivo no sentido de desarmamento geral e completo, inclusive a proibição e eliminação de todos os tipos de armas de destruição em massa, e convencidos de que a proibição de desenvolvimento, produção e estocagem de armas químicas e bacteriológicas (biológicas) e sua eliminação, através de medidas eficazes, facilitará a consecução do desarmamento geral e completo sob estrito e eficaz controle internacional;

Reconhecendo o importante significado do Protocolo em Genebra, de 17 de junho de 1925, para a Proibição do Uso na Guerra de Gases Asfixiantes, Venenosos e Outros e de Métodos Bacteriológicos de Guerra, e conscientes também da contribuição que o referido Protocolo já deu e continua a dar para atenuar os horrores da guerra;

Reafirmando sua adesão aos princípios e objetivos desse Protocolo e concitando todos os Estados a que os cumpram estritamente;

Lembrando que a Assembléia Geral das Nações Unidas tem repetidamente condenado todos os atos contrários aos princípios e objetivos do Protocolo de Genebra, de 17 de junho de 1925;

Desejando contribuir para o fortalecimento da confiança entre os povos e a melhoria geral da atmosfera internacional;

Desejando também contribuir para a realização dos propósitos e princípios da Carta das Nações Unidas;

Convencidos da importância e urgência de serem eliminadas dos arsenais dos Estados, através de medidas eficazes, perigosas armas de destruição em massa, como as que utilizam agentes químicos ou bacteriológicos (biológicos);

Reconhecendo que um acordo sobre a proibição de armas bacteriológicas (biológicas) e à base de toxinas representa um primeiro passo viável no sentido da consecução de acordo sobre medidas eficazes para proibir também o desenvolvimento, a produção e a estocagem de armas químicas, e determinados a continuar negociação para este fim;

Determinados, para o bem de toda humanidade, a excluir completamente a possibilidade de utilização como armas de agentes bacteriológicos (biológicos) e à base de toxinas;

Convencidos de que tal uso repugnaria à consciência da humanidade e de que nenhum esforço deve ser poupado para minimizar este risco, 


\section{Valdi Tutunji}

Convieram no que segue:

\section{ARTIGO I}

Cada Estado-parte na Convenção se compromete a nunca em quaisquer circunstâncias, desenvolver, produzir, estocar ou por qualquer outro modo adquirir ou conservar em seu poder:

1) agentes microbiológicos ou outro agentes biológicos ou toxinas, quaisquer que sejam sua origem ou método de produção, de tipos e em quantidades que não se justifiquem para fins profiláticos, de proteção ou outros fins pacíficos;

2) armas, equipamentos ou vetores destinados à utilização destes agentes ou toxinas para fins hostis ou em conflitos armados.

\section{ARTIGO II}

Cada Estado-parte na Convenção se compromete a destruir ou desviar para fins pacíficos, tão logo seja possível e, em todo caso, num prazo que não exceda nove meses após a entrada em vigor da Convenção, todos os agentes, toxinas, armas, equipamentos e vetores especificados no artigo I da Convenção que estejam em seu poder ou sob jurisdição ou controle. No cumprimento dos dispositivos deste artigo serão observadas todas as precauções de segurança para a proteção das populações e do meio ambiente.

\section{ARTIGO III}

Cada Estado-parte na Convenção se compromete a não transferir a quem quer que seja, direta ou indiretamente, e a não ajudar por qualquer meio, encorajar ou induzir qualquer Estado, Grupo de Estado ou organizações internacionais a fabricar ou adquirir de outro modo quaisquer agentes, toxinas, armas, equipamentos ou vetores especificados no artigo I da Convenção.

\section{ARTIGO IV}

Cada Estado-parte na Convenção tomará, de acordo com seus processos constitucionais, as medidas necessárias para proibir e impedir o desenvolvimento, a produção, a estocagem, a aquisição ou retenção dos agentes, toxinas, armas, equipamentos e vetores especificados no artigo I da Convenção, dentro de seu território, sob sua jurisdição ou sob seu controle, onde quer que seja.

\section{ARTIGO V}

Os Estados-parte na Convenção se comprometem a manter consultas entre si e a cooperar para resolver quaisquer problemas que venham a surgir em relação aos objetivos da Convenção ou à aplicação de seus dispositivos. A consulta e a cooperação nos termos deste artigo também podem ser realizadas através de procedimentos internacionais adequados no quadro das Nações Unidas e de acordo com sua Carta.

\section{ARTIGO VI}

1) Qualquer Estado-parte na Convenção que verifique que outro Estado-parte está 


\section{Guerra biológica}

agindo em violação das obrigações resultantes dos dispositivos da Convenção poderá depositar queixa junto ao Conselho de Segurança das Nações Unidas. Esta queixa deve incluir todas as provas possíveis que confirmem seu fundamento, assim como um pedido de consideração pelo Conselho de Segurança.

2) Cada Estado-parte na Convenção se compromete a cooperar na realização de qualquer investigação que o Conselho de Segurança venha a iniciar de acordo com os dispositivos da Carta, com base na queixa recebida pelo Conselho. O Conselho de Segurança informará os Estados-parte na Convenção dos resultados da investigação.

\section{ARTIGO VII}

Cada Estado-parte na Convenção se compromete a fornecer ou apoiar assistência, de acordo com a Carta das Nações Unidas, a qualquer parte na Convenção que a solicite, se o Conselho de Segurança decidir que tal parte ficou exposta a perigo em conseqüência de violação desta Convenção.

\section{ARTIGO VIII}

Nada nesta Convenção será interpretado como limitando ou atenuando, de qualquer modo, as obrigações assumidas por qualquer Estado por meio do Protocolo para a Proibição do Uso na Guerra de Gases Asfixiantes, Venenosos e outros e de Métodos Bacteriológicos de Guerra, assinado em Genebra, em 17 de junho de 1925.

\section{ARTIGO IX}

Cada Estado-parte nesta Convenção afirma o objetivo reconhecido de uma efetiva proibição de armas químicas e, para este fim, comprometer-se a continuar negociações de boa fé com vistas a chegar brevemente a acordo sobre medidas eficazes para a proibição de seu desenvolvimento, produção e estocagem e para sua destruição, e sobre medidas apropriadas relativas a equipamento e vetores especialmente destinados à produção ou emprego de agentes químicos para fins de armamento.

\section{ARTIGO X}

1) Os Estados-parte na Convenção comprometem-se a facilitar o mais amplo intercâmbio de equipamento, materiais e informação científica e tecnológica para uso de agentes bacteriológicos (biológicos) e toxinas para fins pacíficos e têm o direito de participar nesse intercâmbio. As Partes na Convenção que estiverem em condições de fazê-lo, também cooperarão para maior desenvolvimento e aplicação das descobertas científicas no campo da bacteriologia (Biologia) para prevenção de doenças ou para outros fins pacíficos, para isso contribuindo individualmente ou conjuntamente com outros Estados ou organizações internacionais.

2) Esta Convenção será aplicada de modo tal que impeça prejuízos ao desenvolvimento econômico e tecnológico dos Estados-parte na Convenção ou à cooperação internacional no campo das atividades bacteriológicas (biológicas) pacíficas, inclusive o intercâmbio internacional de agentes bacteriológicos (biológicos) e toxinas, bem como de equipamento para o processamento, uso ou produção de agentes bacteriológicos (biológicos) e 


\section{Valdi Tutunji}

toxinas para fins pacíficos de acordo com os dispositivos desta Convenção.

\section{ARTIGO XI}

Qualquer Estado-parte pode propor emendas a esta Convenção. As emendas entrarão em vigor para cada Estado-parte que as aceite no momento da aceitação pela maioria dos Estados-parte na Convenção e, subseqüentemente, para cada um dos outros Estados-parte, na data em que aceite tais emendas.

\section{ARTIGO XII}

Cinco anos após a entrada das partes na Convenção, ou mais cedo, se for solicitado pela maioria das partes na Convenção por meio de proposta neste sentido aos governos depositários, realizar-se-á em Genebra, Suíça, uma Conferência dos Estados-parte na Convenção para examinar a aplicação da Convenção, com o fim de assegurar o cumprimento dos objetivos do preâmbulo e dos dispositivos da Convenção, inclusive os que se referem à negociação sobre armas químicas. Essa reunião deverá levar em consideração quaisquer novos desenvolvimentos científicos ou tecnológicos que se relacionem com a Convenção.

\section{ARTIGO XIII}

1) A presente Convenção terá duração ilimitada.

2) Cada Estado-parte nesta Convenção, no exercício de sua soberania nacional, tem direito de retirar-se da Convenção se considerar que acontecimentos extraordinários, relativos à matéria de que trata a Convenção, puseram em risco os supremos interesses do País. Para tanto, deverá comunicar essa retirada a todos os demais Estados-parte na Convenção e ao Conselho de Segurança da Nações Unidas com três meses de antecedência. Esta comunicação deverá incluir uma declaração sobre os acontecimentos extraordinários que o Estado em questão considera como tendo posto em risco seus supremos interesses.

\section{ARTIGO XIV}

1) Esta Convenção estará aberta à assinatura de todos os Estados. Qualquer Estado que não assinar a Convenção antes de sua entrada em vigor, de acordo com o parágrafo 3 deste artigo, pode aderir a ela em qualquer tempo.

2) Esta Convenção será sujeita à ratificação pelos Estados signatários. Os instrumentos de ratificação e os de adesão serão depositados junto aos Governos do Reino Unido da Grã-Bretanha e Irlanda do Norte, dos Estados Unidos da América e da União das Repúblicas Socialistas Soviéticas, que passam a ser designados como governos depositários.

3) Esta Convenção entrará em vigor após o depósito dos instrumentos de ratificação por vinte dois governos, inclusive os governos designados como depositários da Convenção.

4) Para os Estados cujos instrumentos de ratificação ou adesão forem depositados após a entrada em vigor da Convenção, esta entrará em vigor na data de depósito dos instrumentos de ratificação ou adesão.

5) Os governos depositários informarão prontamente todos os Estados signatários e 
aderentes sobre a data de cada assinatura, a data de depósito de cada instrumento de ratificação ou adesão e a data de entrada em vigor da Convenção, bem como sobre o recebimento de outras comunicações.

6) Esta Convenção será registrada pelos governos depositários, nos termos do artigo 102 da Carta das Nações Unidas.

\section{ARTIGOXV}

Esta Convenção, cujos textos em inglês, chinês, francês, russo e espanhol são igualmente autênticos, será depositada nos arquivos dos governos depositários. Cópias devidamente certificadas desta Convenção serão transmitidas pelos governos depositários aos governos dos Estados signatários e aderentes.

Em fé do que os abaixo assinados, devidamente autorizados, assinaram esta Convenção.

Feita em três cópias, em Londres, Washington e Moscou, aos dez dias do mês de abril de 1972.

\section{ANEXO II \\ GRUPO DA AUSTRÁLIA \\ LISTA DE EQUIPAMENTOS DE QUE FAZEM USO INSTALAÇÕES BIOMÉDICAS QUE PODEM SER UTILIZADOS NO DESENVOLVIMENTO DE ARMAS BIOLÓGICAS PARA O CONTROLE DA EXPORTAÇÃO}

\section{Instalações com Contenção Biológica Níveis 3 e 4}

Todas as instalações biomédicas que disponham de laboratórios com níveis de contenção 3 e 4 como especificados pelo WHO Laboratory Biosafety Manual (Genebra, 1983) estarão sujeitas a controles de exportação.

\section{Fermentadores}

Fermentadores com capacidade de cultivo de microorganismos patogênicos, vírus e produção de toxinas, sem propagação de aerossóis e que tenham as capacidade igual ou maior que 100 litros. Incluem-se nesta classe de equipamentos todos os biorreatores, quimiostatos e sistemas de fluxo contínuo.

\section{Centrífugas}

Centrífugas, separadores e decantadores capazes de separação de microorganismos patogênicos, sem propagação de aerossóis, que tenham as seguintes características:

(a) capacidade de fluxo de igual ou maior que 100 litros/h;

(b) componentes de aço inoxidável escovado ou titânio;

(c) salas de contenção com duas ou mais portas de isolamento;

(d) capacidade de esterilização in situ em estado fechado. 


\title{
4. Equipamentos de Filtração de Fluxo
}

Equipamentos de filtração de fluxo capazes de separação de microorganismos patogênicos, toxinas e culturas de células, sem propagação de aerossóis, que tenham as seguintes características:

(a) capacidade de filtração igual ou superior a $5 \mathrm{~m}^{2}$

(b) capacidade de esterilização in situ.

\section{Equipamento de Liofilização}

Equipamentos de liofilização esterilizáveis, com capacidade de condensação maior que $50 \mathrm{~kg}$ de gelo em $24 \mathrm{~h}$ e menor que $1000 \mathrm{~kg}$ de gelo em $24 \mathrm{~h}$.

\section{Prédios e Instalações com Contenção Biológica 3 e 4}

(a) Proteção total ou parcial de prédios e ambientes. similares.

(b) Isoladores ou cabines de segurança biológica classe III com padrões de performance

\section{Câmaras de Inalação Aerossol}

Câmaras desenvolvidas para testes de desafio de inalação com microorganismos e toxinas com capacidade igual ou maior que $1 \mathrm{~m}^{3}$.

\section{Outros Equipamentos}

- Equipamentos de microencapsulamento de microorganismos vivos e toxinas na faixa de $10 \mathrm{~m}$ de tamanho das partículas, mais especificamente:

(a) policondensadores;

(b) separadores de fase.

- Fermentadores com menos de 100 litros de capacidade com ênfase especial nos de uso combinado.

- Salas limpas com equipamentos de fluxo de ar, equipadas com filtros HEPA, que possam ser utilizadas como instalações de contenção biológica níveis 3 ou 4.

\author{
ANEXO III \\ GRUPO DA AUSTRÁLIA \\ LISTA DE MICROORGANISMOS QUE DEVEM SOFRER \\ CONTROLE DE EXPORTAÇÃO, EXCETO EM FORMA DE VACINAS
}

\section{1) Vírus}

V1. Vírus Chikungunya

V2. Vírus da Febre Hemorrágica do Congo-Criméia 
V3. Vírus da Dengue

V4. Vírus da Encefalite Eqüina do Leste

V5. Vírus Ebola

V6. Hantavírus

V7. Vírus Junin

V8. Vírus da Febre de Lassa

V9. Vírus da Coriomeningite Linfocítica

V10. Vírus Machupo

V11. Vírus Marburg

V12. Vírus da Varíola dos Macacos

V13. Vírus da Febre do Vale Rift

V14. Vírus da Encefalite da Rússia

V15. Vírus da Varíola

V16. Vírus da Encefalite Eqüina da Venezuela

V17. Vírus da Encefalite Eqüina do Oeste

V18. Vírus da Varíola Branca

V19. Vírus da Febre Amarela

V20. Vírus da Encefalite do Japão

\section{2) Rickettsia}

R1. Coxiella burnetii

R2. Bartonella quintana (Rochalimea quintana, Rickettsia quintana)

R3. Rickettsia prowasecki

$\mathrm{R} 4$. Rickettsia rickettsii

\section{3) Bactérias}

B1. Bacillus anthracis

B2. Brucella abortus

B3. Brucella melitensis

B4. Brucella suis

B5. Chlamydia psittaci

B6. Clostridium botulinum

B7. Francisella tularensis

B8. Burkholderia mallei (Pseudomonas mallei);

B9. Burkholderia pseudomallei (Pseudomonas pseudomallei)

B10. Salmonella typhi

B11. Shigella dysenteriae

B12. Vibrio cholerae

B13. Yersinia pestis

\section{4) Microorganismos geneticamente modificados}

G1. Ou elementos genéticos que contenham seqüências de ácido nucléico associa- 
das com a patogenicidade de quaisquer microorganismos presentes nesta lista.

G2. Ou elementos genéticos que contenham seqüências de ácido nucléico, codificando qualquer toxina ou suas subunidades presentes nesta lista.

\section{5) Toxinas e Subunidades, exceto imunotoxinas}

T1. Toxina botulínica

T2. Toxina do Clostridium perfringens

T3. Conotoxina

T4. Ricina

T5. Saxitoxina

T6. Toxina de Shiga

T7. Toxina do Staphylococcus aureus

T8. Tetrodotoxina

T9. Verotoxina

T10. Microcistina

T11. Aflatoxinas

\section{ANEXO IV \\ GRUPO DA AUSTRÁLIA - LISTA DE ADVERTÊNCIA}

\section{1) Vírus}

WV1. Vírus da Floresta de Kyasanur

WV2. Vírus Doença de Louping

WV3. Vírus da Encefalite do Vale Murray

WV4. Vírus da Febre Hemorrágica de Omsk

WV5. Vírus de Oropouche

WV6. Vírus Powassan

WV7. Vírus Rocio

WV8. Vírus da Encefalite de St. Louis

\section{2) Bactérias}

WB1. Clostridium perfringens

WB2. Clostridium tetani

WB3. Escherichia coli enterohemorrágica sorotipo 0157 e outros sorotipos produtores de toxinas

WB4. Legionella pneumophila

WB5. Yersinia pseudotuberculosis

\section{3) Microorganismos geneticamente modificados}

G1. Ou elementos genéticos que contenham seqüências de ácido nucléico associadas com a patogenicidade de quaisquer microorganismos presentes nesta lista. 
G2. Ou elementos genéticos que contenham sequiências de ácido nucléico, codificando qualquer toxina ou suas subunidades presentes nesta lista.

\section{4) Toxinas e Subunidades, exceto imunotoxinas}

WT1. Abrin

WT2. Toxina colérica

WT3. Toxina tetânica

WT4. Micotoxinas Tricoteceno

WT5. Modecin

WT6. Volkensin

WT7. Viscumin

\section{Referências bibliográficas}

AMERICAN HOSPITALASSOCIATION. Preparedness for Mass Casualties. Final Report Office of Emergency Preparedness U.S. Department of Health and Human Services August, 2000.

AMERICAN PUBLIC HEALTH ASSOCIATION CONTROL OF COMMUNICABLE DISEASES IN MAN, 15th Edition, New York, 1990. Diagnosis and Treatment of Diseases of Tactical Importance to US CENTCOM Forces, 1991. Office of the US Army Surgeon General, Falls Church, VA 22041 (2nd Edition - January 1991).

APIC/CDC Bioterrorism Readness Plan: A Template for Healthcare Facilities. Disponível em: http:www.apic.org

AUSTRALIA GROUP. Export Controls on Materials Used in the Manufacture of Chemical and Biological Weapons, Control List of Dual-Use Chemicals: Commercial and Military Application.

BARLETTA, M. \& SANDS, A. Nonproliferation Regimes at Risk. Occasional Paper No. 3 Monterrey Nonproliferation of International Studies, 1999.

BOZHEYEVA, G. KUNAKBAYEV, Y \& YELEUKENOV, D. Former Soviet Biological Weapons Facilities in Kazakhstan: Past, Present and Future. Occasional Paper No. 3 Monterrey Nonproliferation of International Studies, 1999.

CAMERON, G. PATE, J. MCCAULEY, D. \& DEFAZIO, L. 1999 WMD Terrorism Chronology: Incidents Involving Sub-National Actors and Chemical, Biological, Radiological and Nuclear Materials. The Nonproliferation Review/Summer, 2000.

CDC. Public Health Emergency Response: The CDC Role. Disponível em: http:// www.bt.cdc.gov/DocumentsApp/ImprovingBioDefense/ImprovingBioDefense.

CDC. Biological and Chemical Terrorism: Strategic Plan for Preparedness and Response Recommendation of the CDC Strategic Planning Workgroup. MMWR Vol. 49 No. RR-4 April 21, 2000 
CDC. Bioterrorism Preparedness and Response: A National Public Health Training Plan. CDC Center for Disease Control and Prevention September, 2000

DUNCAN, A. \& JOHNSON, K.G. Strengthening the BWC: Lessons from the UNSCOM Experience. The Nonproliferation Review/Winter, 1997.

FEDERATION OFAMERICAN SCIENTISTS. Beyond Verex: A Legally Binding Compliance Regime for the Biological and Toxin Weapons Convention. Disponível em: http:// www.faz.org/bwc/verex.html

FUNASA/Fundação Nacional de Saúde. Carbúnculo ou Antraz: Informação Geral. Nota Técnica. Outubro, 2001.

GEISSLER, E. Biological and Toxin Weapons Today. Stockholm International Peace Research Institute, Oxford University Press, New York, 1986.

GEISSLER, E. Courtland-Moon, J. Biological and Toxin Weapons: Research, Development, and Use from Middle Ages to 1945. Stockholm International Peace Research Institute, Oxford University Press, New York, 1999.

HOFFMANN, B. Terrorism and WMD: Some Preliminary Hypotheses. The Nonproliferation Review/Spring-Summer, 1997.

KAUFFMANN, A.F. MELTZER, M.I. \& SCHMID G.P. The Economic Impact of a Bioterrorism Attack: Are Prevention and Postattack Intervention Programs Justifiable? Emerging Infectious Diseases Vol. 3 No. 2 April-June, 1997.

MANDELL, G., DOUGLAS, R., BENNETT, J. Health Aspects of Chemical and Biological Weapons. Report of WHO Group Consultants, WHO, Geneva, 1970. Principles and Practice of Infectious Diseases, 3rd Edition. Churchill Livingstone, New York, 1990.

NATO. Handbook on Medical Aspects of NBC Defensive Operations. Part 3 (Chemical) (AMedP-6(B)).

NATO. Handbook on the Concept of Medical Support in NBC Environments. (AMedP-7(a).)

PEARSON, G. The Threat of Deliberate Disease in the 21st Century in Biological Weapons Proliferation: Reasons for Concern, Courses of Action, (The Henry L. Stimson Center: Washington, D.C.: January 1998): 30-33; US Arms Control and Disarmament Agency; Washington Post; US Congress: Senate Committee on Governmental Affairs; Office of Technology Assessment; Office of Secretary of Defense.

PEARSON, G. New Scientific and Technological Developments of Relevance to the Fifth Review Conference. Report of the NATO Advanced Research Workshop Prague, Czech Republic: 31 may-2 june, 2001.

PEARSON, G. Strengthening the Biological and Toxin Weapons Convention. Progress in Geneva Quarterly Review No.15 June, 2001.

PEARSON, G. Why Biological Weapons Present the Greatest Danger. Seventh International Symposium on Protection Against Chemical and Biological Warfare Agents, Stockolm, 2001.

PEARSON, G. The Composite Protocol Text: Na Effective Strengthening of the Biological and Toxins Weapons Convention. 2001. 
ROBERTS, B. Controling the Proliferation of Biological Weapons. The Nonproliferation Review/Fall, 1994.

SINAI, J. Libya's Pursuit of Weapons of Mass Destruction. The Nonproliferation Review/ Spring-Summer, 1997.

SPALDING, S.E. The Deutch Comission Report: An Overview. The Nonproliferation Review/ Fall, 1999.

TUCKER, J.B. Evidence Iraq used Chemical Weapons during the 1991 Persian Gulf War. The Nonproliferation Review/Spring-Summer, 1997.

TUCKER, J.B. SANDS, A. Averting Failure of the Biological Weapons Nonproliferation Regime. Discussion Paper for Strategy Session on "Coping with Nonproliferation Crises" Washington, D.C., 3-4 Novembro, 1999.

UN Ad Hoc Group of Governmental Experts to Identify and Examine Potencial Verification Measures from a Scientific and Technical Standpoint. Report BWC/CONF III/VEREX/ 9, Geneva, 1993.

UN List of States Parties to the Convention on The Prohibition of the Development, Production and Stockpilling of Bacteriological (Biological) and Toxin Weapons and on their Destruction. BWC/Conf. V/PC/ INF. 5. 20, april, 2001.

US ARMY. Manual of NBC Defence Training on Land. (AC No 71328/AP 3395, 2nd Edition/BR 8456.) Pamphlet No 6. ANBC Guide for Medical Personnel.

WHEELIS, M. Investigating Disease Outbreaks under a Protocol to the Biological and Toxin Weapons Convention. Emerging Infectious Diseases Vol. 6 No. 6 NovemberDecember, 2000.

WIENER, S. \& BARRET, J. Trauma Management for Civilian and Military Physicians. W. B. Saunders and Co., Philadelphia, PA, 1986.

ZANDERS, J.P. Assessing the Risk of Chemical and Biological Weapons Proliferation to Terrorists. The Nonproliferation Review/Fall, 1999. 